\title{
Equipment planning strategy for liners: empty container repositioning across alliances
}

Equipment planning strategy for liners

\author{
Hang Fa Tong and Hong Yan \\ Department of Logistics and Maritime Studies, \\ The Hong Kong Polytechnic University, Hong Kong, China
}

89

Received 2 November 2017 Revised 28 December 2017 2 February 2018 Accepted 6 March 2018

\begin{abstract}
Purpose - This paper examines the possible cooperation options in terms of empty container repositioning across alliances for shipping lines based in the Greater China Region (China, Taiwan and Hong Kong SAR), after the three global shipping alliances reformed in April 2017.

Design/methodology/approach - This paper offers a comprehensive review to the latest shipping alliances and introduces a new cooperative dimension among shipping lines based in the Greater China Region which are member of different shipping alliances.

Findings - Cooperation among shipping lines in the Greater China Region in terms of empty container handling is possible in terms of resource sharing among shipping lines across alliances that fosters mega shipping line formation in the future.

Practical implications - Shipping lines should review their current empty container repositioning strategies and explore cooperation among non-alliance members having headquarters in proximity for quick responsiveness in empty container repositioning plan and execution.
\end{abstract}

Originality/value - This is a research directly analyzing the empty repositioning plan of the major shipping lines and their major service routes, fleet and containers.

Keywords Repositioning, Empty container, Shipping alliances, Shipping lines

Paper type Research paper

\section{Introduction}

\subsection{Liners and alliances}

Shipping lines or liners operates with very similar business nature forming a container shipping industry that can be clearly distinguished from other industry in the water transport sector (Sys, 2009)[1]. Cooperation and competition could be found concurrently for liners having vessel callings in the same or nearby port and region. Shipping service loops, for example, from Fast East to Europe or Fast East to West Coast of North America, offered by a particular liner solely is rarely found since a few decades ago as major global liners form shipping alliances for the purpose of economies of scale and workload balancing (Lim, 1998). A lower unit cost could be achieved while highly competitive, reliable and regular shipping services are delivered to a larger set of customers, including those with highly irregular shipping services demand pattern. These member liners contractually cooperate on a routine basis according to the alliance service agreement while they theoretically could compete with each other. Within a global liner, shipping scheduling and network design for laden container movement form the core part of the liner services that a great amount of effort is paid in studying the best global scheduling networks for leading liners, for example,

(c) Pacific Star Group Educational Foundation.

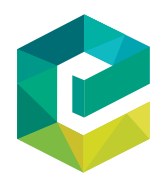

Maritime Business Review Vol. 3 No. 1,2018 pp. $89-106$ Emerald Publishing Limited $2397-3757$ 
MABR

3,1

90

a recent study by Agarwal and Ergun (2017). The best business performance is planned based on the good cooperating relationship and agreement among alliances. Alliance members are required to pool in their vessel(s) at pre-defined timeframe for the required weekly regular service loop delivery according to the contractual agreement which remains effective until the alliance agreement ends, which is usually more than one year. They share vessel capacity among alliance members. Member liners are familiar with each other after a period of cooperation, in terms of vessel capacity demand required for laden containers, and additional customer demand swap from one member liner to another, is usually difficult to be served at the target minimum cost as the winner needs to buy additional vessel capacity from the loser in a particular customer game. Therefore, competition among member liners exist but not as vigorous as observed from those across alliances. On the other hand, cooperation among liners across alliances is rarely found due to a closer collaborating relationship with member liners from the same alliance. The closer working relationship could eventually be a good starting point for a mega liner formation by those collaborating liners bonded by the alliance agreement. A liner could dramatically increase her market shares via acquisition, as the most efficient and effective option (Alexandrou et al., 2014). The buyer liner shall own an enlarged vessel and container fleets and apply them to her existing or expanded service loops immediately, without going through the long process of ship order, building, testing and acceptance processes. This paper is to explore the latest alliances' development and examine possible acquisition and cooperation options for shipping lines based in the Greater China Region by proposing a new cooperation dimension across alliances on empty container repositioning (ECR) for liners with headquarters in proximity. Fulfilling ad hoc empty container demand becomes possible and routine with strategic decision made timely among liners across alliances which pool-in certain amount of empty containers at agreed location on a pre-defined effective period. This critical period is measured by hours before any concerned vessel departs from the empty container surplus location where empty containers are available for repositioning.

\subsection{Empty container repositioning}

ECR has increasing attracted scholarly attention in parallel to the shipping alliances related topics in the past decades. Different allocation policies were explored and reviewed without consideration of forming shipping alliance focusing on empty container collaboration (Dong, 2013; Dong and Song, 2009; Song and Carter, 2009). Some studies proposed strategies on empty container logistics without considering possible synergy achieved by decision makers or empty container supply locations in proximity (Epstein et al., 2012). Other than the strategy, new idea is also proposed on the physical structure of the empty container that achieve saving on vessel capacity after container folding during oceanic ECR process. Higher repositioning efficiency is achieved without considering the possible cost and difficulty of the folding operations in different ports (Moon et al., 2013; Chao and Lin, 2017). Some case studies are available for a closer review to the various practical aspects on ECR without exploring to the possible to form any new cooperative strategies with competing liners across alliances for ECR as main focus (Lu et al., 2006). It is well observed that ECR problems draw high attention on the possible variation in the order quantity or cost reduction within a particular liner only, without considering possible collaboration among liners out of their belonging alliances or across alliances (Song and Dong, 2011). Alliance service quality is not studied in terms of the effectiveness of ECR despite it is one of the crucial factors for liner businesses (Thai, 2008; Sys, 2009; Panayides and Wiedmer, 2011). 


\subsection{Quantity decision vs cost estimation}

According to a latest review study summarizing ECR-related problems studied in the past decades, two broad problem types are concluded: quantity decision and cost estimation (Lee and Song, 2017). For quantity decision, it helps liners to make decision on the optimal amount of empty containers to be kept at each port and how they move for demand fulfillment independently. Quantity decision forms a base for subsequent cost estimation and improvement initiatives. To determine the optimal quantity, mathematical models are classified into two streams: network flow models with origin-destination based matrices specifying the amount of empty containers required on each arc in a network or inventory control models that output decision-making rules for the amount of empty containers to be input/out to/from a point of consideration, for example, a seaport or an inland depot. Theoretically, in a particular port or terminal, when a vessel is loaded with containers, the fundamental target is to load as many profitable laden containers as possible instead of the empty container without direct profit making. This is similar to the idea of occupying the full batch or lot size in a production line to achieve the highest economies of scale. In reality, the amount of empty containers to be repositioned varies in each vessel call, due to the a few reasons:

- the available vessel capacity varies in each vessel call;

- the demand in the deficit locations which require empty container replenishment varies along the time;

- the supply of empty container from the surplus locations also varies; and

- the size of the vessel in each vessel call may also vary, especially when different vessels are pooled in by multiple liners for an alliance service loop.

Therefore, it is a dynamic process requiring decision from empty equipment flow team in the territorial or headquarter level to make the final decision. In general, empty containers are transported with lower priority when competing for a vessel capacity space with a laden container, especially during peak season when shipment is agreed with a profitable service charge. Nevertheless, without adequate amount of empty containers repositioning back from the surplus location, for example, a port in Europe or West Cost of North America, the amount of empty containers in the demanding locations, for example, in a port in Asia shall be lowered to the demand level. The empty container accumulate back in the surplus locations shall incur cost to liners too. Therefore, certain amount of vessel capacities must be allocated in the returning trip of most of the long-haulage service loops to ensure a reasonable balance between the surplus and deficit territories, regions or locations. Liners may arrange for ECR across trade lanes, for examples, supply empty containers to the demanding ports in Asia when the mega vessel transporting huge amount of empty containers back to Asia. The process is carried out in common ports, Port P3 and Port P4 within Alliance A1 as illustrated in Figure 1. The process is limited to the services within a liner, or within an alliance where liners' arrangements are limited to the pre-defined services cooperating with liners in the same alliance. It will be much flexible if the liner could also consider and cooperate with liners in other alliances where other common ports shall be found.

\subsection{Empty container cooperation in common ports}

The key successful factor is to ensure lowest cost of repositioning that full capacity should be used after loading all of profitable laden containers from the surplus location. The available capacity for ECR varies in each vessel call for each origin-destination (O-D) pair, 


\section{MABR}

3,1

\section{2}

Figure 1.

Additional common ports from other alliance services for ECR

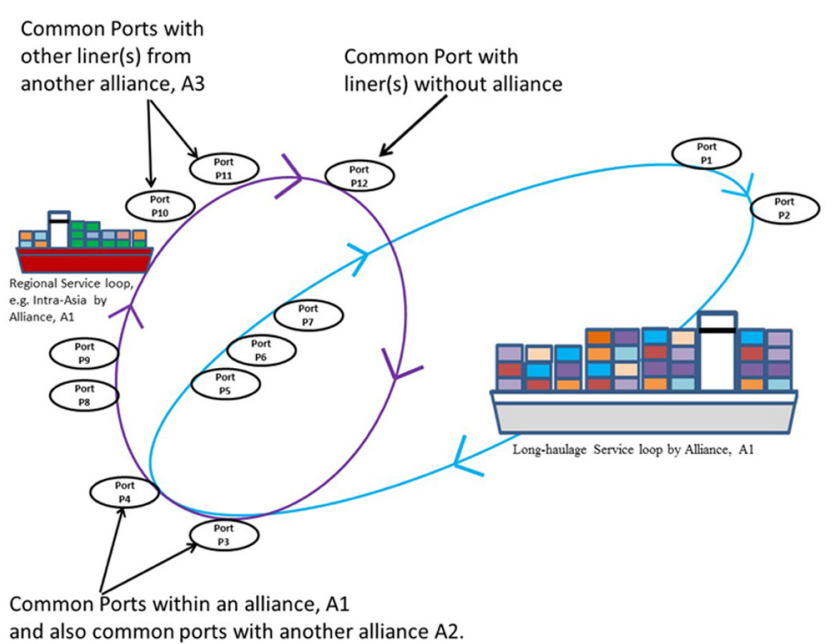

depending on the amount of capacities occupied by laden containers. The ideal case is to discharge all the empty containers once they complete such an origin-destination pair, for example, Port P2-Port P3, and immediately release all the vessel capacity for laden containers to be loaded in Port P4 onwards. This is usually not achieved due to the demand in Port P3 is not big enough, and also the other Ports along the service loop, such as Port P4, P5, P6 and P7 require certain amount of empty containers replenishment too. Therefore, there is situation that laden container are delayed due to the lack of vessel capacity occupied by empty container for the purpose of repositioning across ocean. Sometimes an individual liner may try to rectify the situation by arranging empty container supplied by other services from other trades, for example, Intra-Asia trade to fulfill the higher demand, as long as there is/are common port(s), such as Port P4 and Port P5. However, once this is arranged, the demand for the Intra-Asia services may not be enough. If there is possibility to use any surplus empty containers stored in the port along the service loop, which are the common ports with other liner(s) or alliances, such as Port P4 and Port P5 (common ports with Alliance A2 on long-haulage services, for example), Port P10 and Port P11 (common ports with Alliance A3 for regional services, for example) and Port P12 (common port with liner without any alliance), the flexibility to arrange for empty container by a liner empty equipment flow will be much higher to achieve the best amount of empty containers repositioned with the best and optimal cost due to economies of scale, and avoid diseconomies effectively. In this case, the best volume or target lot size for each origindestination pair, without leaving vessel capacity unused for each origin-destination pair is achieved.

On the other hand, instead of having cooperation in liner level within an alliance, a big step is recently taken by two leading shipping companies in the Greater China Region. The long discussing topic over the acquisition decision on OOCL by China COSCO Shipping (formed by two publicly owned shipping companies in PRC: COSCO and China Shipping in 2016) is confirmed by the involved companies on the 8 July 2017. The acquisition price is announced as US\$6.3bn. The announcement includes the statement on the existing organizational structure in OOCL. The statement emphasizes no change shall take place within two years since the date of acquisition. This acquisition decision increases the market 
share of China COSCO Shipping from 7.9 to 10.6 per cent immediately, and influences the market structurally. First, the size of the China COSCO Shipping has similar market share to the original biggest alliance member, CMA CGM within the reformed alliance, OCEAN Alliance. The structure of OCEAN Alliance is simpler and closer to the two-member only alliance, 2M Alliance formed by Maersk and MSC. The new China COSCO Shipping is believed to be further improved and operated with more commercial shipping lines' thinking via OOCL, company declared herself as IT strategic or IT innovative based shipping line (Leng, 2003), out of the original country-owned or public organization owned by the Government of China. Other than CMA CGM, Evergreen is another alliance member under OCEAN Alliance, with headquarter based in Taiwan with market share 4.8 per cent, which is higher than that of OOCL (2.7 per cent) before acquisition. Evergreen becomes the smallest alliance member in OCEAN Alliance now. New thinking on the possible further acquisition by China COSCO Shipping on Evergreen starts again. It is doubted that if China COSCO Shipping, shall eventually acquire all the key shipping lines from Taiwan and form a super shipping line with headquarter or management team based in Asia or China. This might be a possible way to compete with the top leader, Maersk or the 2M alliance which have high impact and leading market share on Trans-pacific (America-Asia), Trans-Atlantic (Europe-Asia) and Intra-Asia trade lines. This new thinking might be released in a foreseeable future for the blooming economic development for countries along the One-BeltOne-Road (OBOR) pathways.

\subsection{Major acquisitions in the past decades}

According to a public report issued by Drewry about liner consolidation in March 2016, there were many acquisition found in the past few decades in the West that smaller shipping lines were acquired (or merged) with buyer with bigger company size in terms of number of vessels or market share (Figure 2). As the first few acquisitions took place in Europe, the trend is observed as spreading over to other territories as indicated by the arrows conceptually in Figure 2. Many scholars and industrial leaders suspect that future shipping market shall be dominated by a few mega shipping lines. When this comes to true, these

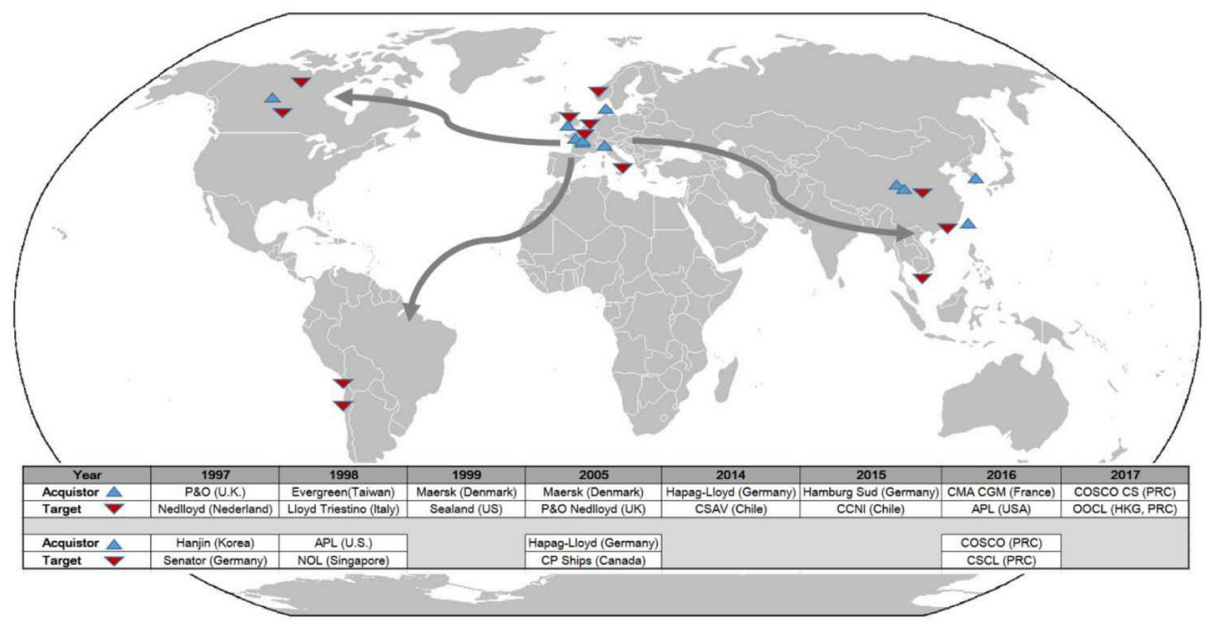

Source: Drewry Report 2016
Equipment planning strategy for liners

93
Figure 2.

An overview to liner acquisitions since the 1990s until 2017 by geographical locations 
MABR

3,1

94

mega leaders might not need to form alliance any more. It is also believed that the final set of leaders might have their own territories geographically, covering North-America, Western Europe and Asia. Small to median size shipping lines hardly survive and compete with the mega liners. They might be acquired eventually or bankrupted due to bad financial conditions over a prolonged timeline (e.g. Hanjin Shipping). For shipping lines with headquarters based in Asia, it is not clear in this moment if the mega leader formation is being taken place. It is also not clear that if the shipping lines with headquarters based in Taiwan shall be willing to be acquired when time comes. Other than political factors, there are many more business considerations that prohibit further acquisition decision. China COSCO Shipping needs to think over and manage without affecting the existing harmonic situation among Chinese Shipping lines in the Great China Region, with the given special situation between China and Taiwan (Yang, 2016; Lin and Chang, 2016).

The key topics discussed in this paper focused on the future development of the shipping lines based in China, Taiwan and Hong Kong SAR:

- Will a mega liner raised from Asia in the soon future, and when?

- Is empty container pool set up by shipping lines across alliances in the Greater China Region a good cooperation before any mega liner raised in Asia in the future?

\section{Acquisition among liners}

\subsection{Shipping line business operations form and similarity}

Shipping lines offer shipping services in terms of service loops that vessels are allocated to call each of the belonging ports along a service loop in each port on weekly basis (Chen and Yahalom, 2013). This gives similar operations among shipping lines regardless to the company size. Each company has headquarters that each of them is to branch to territories and further branches to regional offices. If the company is big enough, there might be a few headquarters, that one of the headquarters where CEO or most of the board of directors reside is the super headquarters taking care all the strategic and long-term decision. If the company is a smaller one, her headquarters might be covering a territory only that branches to a few regional offices. The need to have regional offices is to serve for both outbound and also inbound customers in the region that oversee a few or at least one port operations where her vessel calls regularly. If the port is a transshipment port, the regional office is to take a keen role in coordinating with the various regional offices or territory as well. Organizational structure is very similar among shipping lines even the actual port of callings might be different, and the alliance formed by these liners are virtually sharing similar knowledge on empty positioning strategy as well (Li et al., 2016). To quickly expand the service scope without a big impact to her existing organization, the buyer focus on both company size and vessel volume of the candidate company for acquisition feasibility analysis.

\subsection{Stakeholders of a shipping line: how decision is made and released to regional offices}

Regional offices are profit making frontlines that Sales and Marketing is to explore, secure and serve local customers, while territorial offices (or even headquarter(s)) are the ones to deal with mega or VIP clients with tremendous amount of cargoes transported via multiple trade lanes. After business deals are confirmed, the service delivery is down to regional level. In other words, the three-levels format, headquarters, territorial and regional level are common for most of the global shipping lines, as they all share the same globe and differ in terms of business scope in terms of regions and ports only. Headquarter location indicates 
the management team's belonging or preferred country (sometimes named as home country) where the final business revenue will be collected and taxed that contribute to the country economic growth and development, other than employment. Sometimes, even business volume observed in the home country for a shipping line, the business revenue might be blooming due to the intensified business development and profit obtained from ports of many other countries. Better taxation and founding history in the home country are possible reasons for a global liner to stay with her home country. Family business may also be another reason too. When alliance is to be formed, shipping lines tends to join alliance separately with shipping lines emerged from other territories for the sake of globalization (Figure 3).

\subsection{Key considerations by a buyer liner}

The key consideration is probably the vessel and container fleets that are being used in term of quantity and quality. For vessel fleet in particular, its characteristics, such as average fleet age, vessel size, vessel nature and active leasing agreement, if any, are all key considerations by the buyer liner. For leasing agreement in particular, buyer needs to consider the leasing term (voyage charter, time charter or bareboat charter, etc.) seriously before a final decision is made according to the data obtained from Alphaliner Report in 2017 (Figure 4). If vessel fleet includes a relative high portion of vessels with leasing contracts expired in near future, the fleet size shall be diminished significant unless contract renewal arrangement is made timely. Renewal agreement involve significant among of cash flow that buyer may need to pay on top of the acquisition cost. On the contrary, if the leasing time line is far ahead, buyer-company needs to consider the regular cash flows along the future timeline that might cover a few shipping cycles. Cutting a long-term contract require penalty cost that is usually not preferred.

For OOCL in particular, over 50 per cent of the operating vessels are not physically belonged to OOCL. Vessel leasing company sign leasing contract with OOCL and allow the naming of the vessel under OOCL brand name for long-term contract over 10 years or above. It is a typical shipping line with a significant number of vessels chartered with third parties. Despite economies of scale has been taken as a key business strategy in many leading liners in terms of number of vessels, containers and servicing scopes and networks (Lim, 1998), it is recently argued that the size of a shipping line determines the business performance without full grantee on economies of scale (Yip et al., 2012). Therefore, OOCL performance may indicate the performance of a majority of shipping lines but not the top few leaders in the concerned period in 2016. During the leasing period include 2016 and onwards, regular

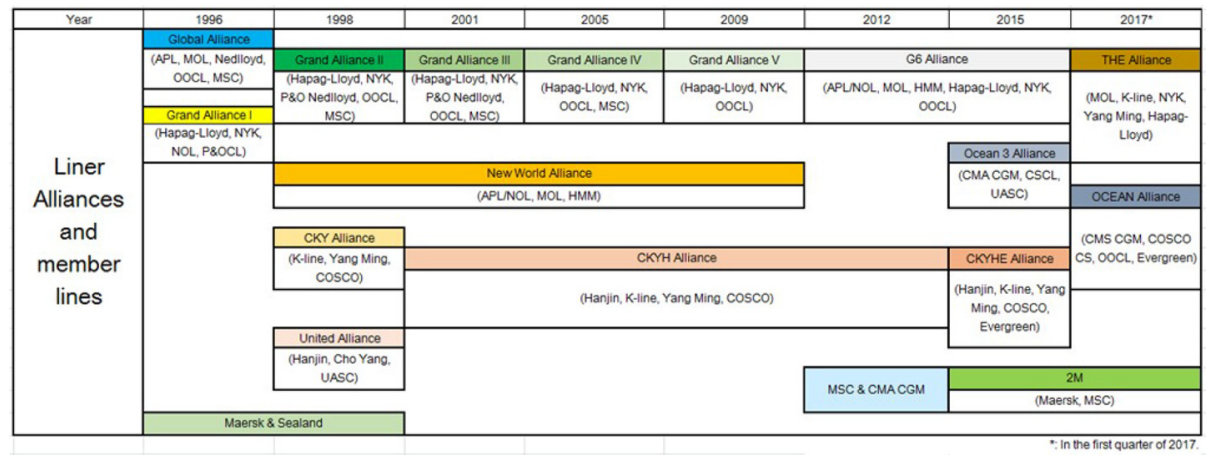

Equipment planning strategy for liners

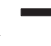




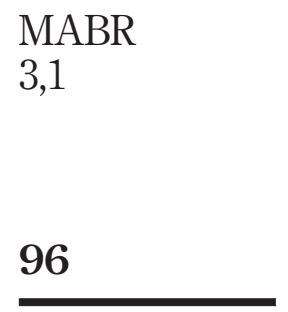

Figure 4.

Top liners with leasing nature: vessel chartered vs market share by percentages

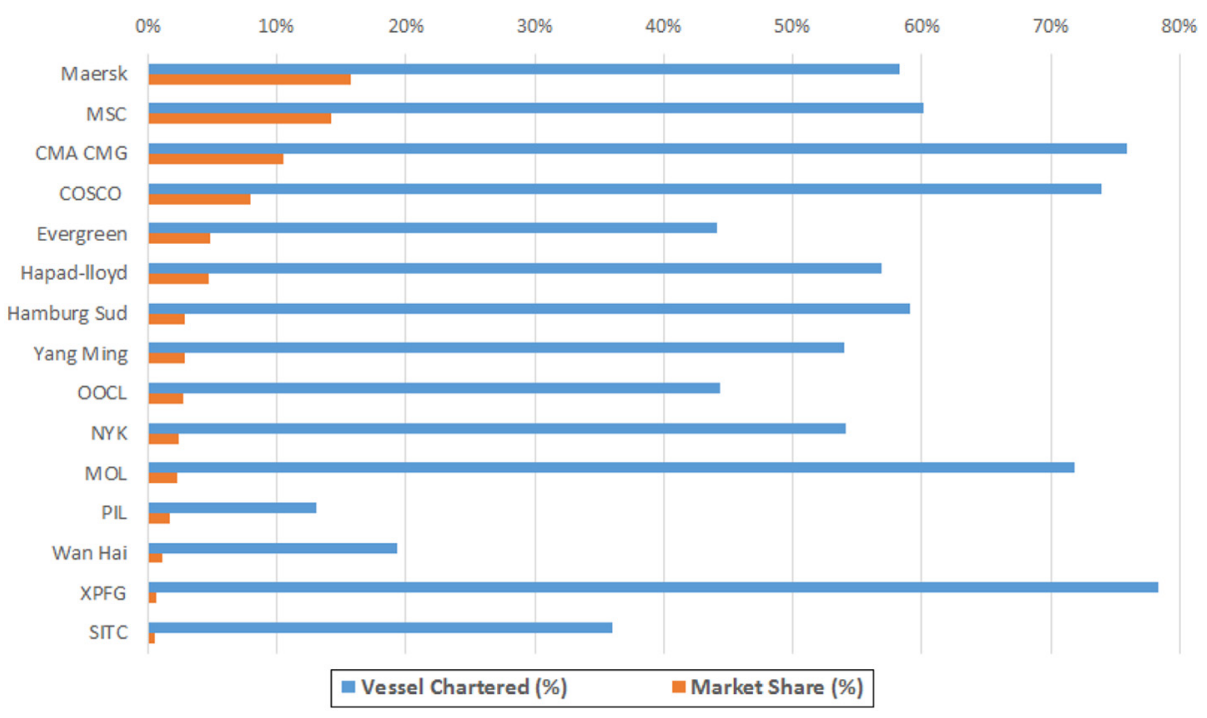

Source: Alphaliner Report 2017

instalments are paid by OOCL to leasing company regardless to the business performance of the lease holder or lessee, OOCL. At the end of the leasing process, a significant lump sum payment is often required for the required inspection and repair needs before return to the owner, the leasing company. These are significant cash flows that buyer-company needs to pay high attention.

On the other hand, if high proportion of vessels owned by the candidate liner, the depreciation cost is higher due to the increase set of asset but a higher flexibility for future cash flow arrangement is allowed. Buyer-company needs to consider efficient deployment of the merged fleet in both peak, normal and low seasons, and keep an active fleet with adequate but not over capacity. To remain competitive, sub-lease out arrangement might be arranged before market move down or new leasing arrangement will be considered before market move up for sizable liner. Buy company decision is therefore affected by the market conditions to avoid under- or over-capacity once acquisition take place. Different candidate liners are compared and reviewed to ensure highest flexibility in cash flow arrangement. Sometimes, a leading buyer company may acquire smaller candidate instead of candidate with similar size which has lower number of vessels as vessel leasing arrangement is common for global liners. The scale must be manageable and flexible enough without adverse impact to the buyer company financially after acquisition.

\subsection{Short-term business performance}

Other than the candidate company size and expense due to vessel leasing, the company business stability is also one of the key review criterions by the buyer company. Short-term performance does not affect too much. For example, OOCL has performed negatively in 2016 in terms of Profit-and-Loss summary released in the 2016 annual report (Table I). It seems to be declining, but the declining rate is not as fast as observed in other shipping lines, such as Evergreen and Wan Hai. When the shipping market is experiencing downturn, it is normal 


\begin{tabular}{|c|c|c|c|c|c|c|c|}
\hline & Q4 2016 & Q4 2015 & Change (\%) & FY 2016 & FY 2015 & Change $(\%)$ & $\begin{array}{l}\text { Equipment } \\
\text { nlanning }\end{array}$ \\
\hline \multicolumn{7}{|l|}{ LiFTings (TEU's) } & strategy fo \\
\hline Trans-Pacific & 439,620 & 336,556 & +30.6 & $1,558,495$ & $1,318,025$ & +18.2 & \\
\hline Asia/Europe & 264,410 & 206,600 & +28.0 & 950,649 & 893,807 & +6.4 & \\
\hline Trans-Atlantic & 104,323 & 95,232 & +9.5 & 395,927 & 365,773 & +8.2 & \\
\hline Intra-Asia/Australasia & 859,196 & 749,331 & +14.7 & $3,175,611$ & $2,998,269$ & +5.9 & \\
\hline Total All Services & $1,667,549$ & $1,387,719$ & +20.2 & $6,080,682$ & $5,575,874$ & +9.1 & \\
\hline \multicolumn{7}{|c|}{ Total Revenue (USD OOOs) } & \\
\hline Trans-Pacific & 496,112 & 441,459 & +12.4 & $1,723,268$ & $1,908,483$ & -9.7 & \\
\hline Asia/Europe & 217,663 & 177,119 & +22.9 & 765,798 & 883,651 & -13.3 & Table \\
\hline Trans-Atlantic & 129,863 & 139,475 & -6.9 & 517,530 & 569,313 & -9.1 & $\begin{array}{r}\text { Iable } \\
\text { OOCL Annu }\end{array}$ \\
\hline Intra-Asia/Australasia & 458,799 & 422,592 & +8.6 & $1,694,553$ & $1,857,470$ & $\begin{array}{r}-8.8 \\
-99\end{array}$ & Performance in 201 \\
\hline Total All Services & $1,302,437$ & $1,180,645$ & +10.3 & $4,701,149$ & $5,218,917$ & -9.9 & $\begin{array}{l}\text { Performance in } 2016 \text { : } \\
\text { liftings and revenue }\end{array}$ \\
\hline \multicolumn{7}{|c|}{ Source: OOCL Annual Report 2016} & by tradelan \\
\hline
\end{tabular}

to compare companies with similar size and choose the one with the least negative value. For OOCL in particular, it is well-known for her IT-innovation and process efficiency that highly valued by her customers worldwide. She passed the economic crisis in early 1980s in the past century and develops highly efficient enterprise systems that won representative prizes and awards. The enterprise system is deployed worldwide with large amount of cost contributed to its IT research and development. When cloud computation was still a very new topic 15 or 20 years before, the company has vision to invest on the technical development. Other than users from OOCL internally, the system is also purchased by OOCL competitors, include COSCO and NYK over 10 years before. This indicates OOCL core values and competence other than an ordinary shipping company. The buyer company, China COSCO Shipping, could be improved via the blending process after acquisition and push the merged company for improvement with much faster pace with human resources directly absorbed from OOCL to China COSCO shipping.

\subsection{Company culture and compatibility}

Acquisition might lead to company issues such as cultural conflict, if the candidate is very different from the buyer company, such as language, educational and valuation. If conflict outbreaks in headquarter management level, the impact shall be influential that lead to unexpected company political problem that highly experienced decision maker might choose to leave and join competing liners elsewhere. On the other hand, if the headquarters locate in the same territorial or time zone area, usually common language, culture and communications means are available for prompt blending process of the two company executives. After the acquisition of OOCL by China COSCO Shipping, the remaining shipping lines with stakeholders or headquarters in the Greater China region all locate in Taiwan. They are Evergreen, Yang Ming and Wai Hai with market shares to be 4.8, 2.8 and 1.1 per cent, respectively (Table II), as obtained from Alphaliner Report issued in 2017 as well as individual company annual report of the concerned liners in 2017.

Other than political barrier that might hinder further acquisition by China COSCO Shipping to these potential candidate companies in Taiwan, these companies are good candidates for acquisition. Their market share added up to be 9 per cent in 2017. If China COSCO Shipping acquires these three candidates step by step or all other within a short time horizon, say within 2-3 years, the final resulting market share shall be increased and close to 


\section{MABR \\ 3,1}

\begin{tabular}{|c|c|c|c|c|}
\hline Shipping line & Fleet capacity (TEU) & Active vessel (Count) & $\begin{array}{l}\text { Market share by } \\
\text { fleet capacity }(\%)\end{array}$ & HQ location \\
\hline Maersk & $3,250,668$ & 620 & 15.70 & Denmark \\
\hline MSC & $2,936,553$ & 490 & 14.20 & Switzerland \\
\hline CMA CGM & $2,165,570$ & 447 & 10.50 & France \\
\hline COSCO & $1,639,692$ & 294 & 7.90 & China \\
\hline Evergreen & 989,592 & 187 & 4.80 & Taiwan \\
\hline Hapag-Lloyd & 978,573 & 169 & 4.70 & Germany \\
\hline Hamburg Sud & 594,327 & 115 & 2.90 & Germany \\
\hline Yang Ming & 576,269 & 100 & 2.80 & Taiwan \\
\hline OOCL & 555,124 & 91 & 2.70 & Hong Kong, SAR \\
\hline UASC & 520,254 & 54 & 2.50 & U.A.E. \\
\hline NYK & 594,699 & 99 & 2.40 & Japan \\
\hline MOL & 540,942 & 78 & 2.30 & Japan \\
\hline HMM & 468,998 & 68 & 2.30 & Korean \\
\hline K-Line & 362,708 & 62 & 1.80 & Japan \\
\hline PIL & 353,552 & 134 & 1.70 & Singapore \\
\hline ZIM & 295,170 & 64 & 1.40 & Israel \\
\hline Wan Hai & 223,110 & 87 & 1.10 & Taiwan \\
\hline XPFG & 151,206 & 90 & 0.70 & Taiwan \\
\hline KMTC & 125,887 & 61 & 0.60 & Singapore \\
\hline SITC & 99,997 & 77 & 0.50 & China \\
\hline Total & $17,422,891$ & 3387 & 83.50 & \\
\hline
\end{tabular}

Table II.

Top 20 shipping lines with key business measures and headquarter location

Source: Alphaliner Report 2017 and individual liner's company annual report 2017

20 per cent. This could make China COSCO Shipping ahead of the existing market leader, Maersk, and become the world number 1 shipping line. However, Evergreen is a member of the reformed OCEAN alliance already with China COSCO Shipping now, whereas Yang Ming is a bit far away. She is member of the other reformed THE alliance now. Wan Hai does not belong to any global alliance in this moment. Therefore, Evergreen might be the most possible first candidate for China COSCO Shipping consider for acquisition, followed by Wan Hai and Yang Ming (Table III) as obtained from Alphaliner Report issued in 2017.

Table III.

Compare market share $(\%)$ of the major alliances in the first quarter of 2017

\begin{tabular}{|c|c|c|c|}
\hline Alliance & Member liner & Market share by fleet capacity (\%) & Total market share $(\%)$ \\
\hline \multirow[t]{2}{*}{$2 \mathrm{M}$} & Maersk & 15.70 & 29.90 \\
\hline & MSC & 14.20 & \\
\hline \multirow{4}{*}{ OCEAN } & CMA CGM & 10.50 & 25.90 \\
\hline & COSCO & 7.90 & \\
\hline & OOCL & 2.70 & \\
\hline & Evergreen & 4.80 & \\
\hline \multirow[t]{7}{*}{ THE } & Hapag-Lloyd & 4.70 & 18.80 \\
\hline & Yang Ming & 2.80 & \\
\hline & UASC & 2.50 & \\
\hline & NYK & 2.40 & \\
\hline & MOL & 2.30 & \\
\hline & HMM & 2.30 & \\
\hline & K-Line & 1.80 & \\
\hline \multicolumn{2}{|c|}{ Total Market Share (\%) } & & 74.60 \\
\hline
\end{tabular}




\subsection{Further acquisition feasibility and timeline}

Despite Evergreen seems to be the most possible candidate as the next acquisition target, Yang Ming gives a bigger coverage in terms of alliance membership. If China COSCO Shipping acquires Yang Ming, virtually she could joins more than one alliance as she does now (OCEAN alliance). She will become the first ever shipping line with membership across multiple alliances. This might enable a much higher synergy in terms of service coverage globally. However, acquisition timeline is a multiple of five years or above, starting from the point of consideration until the final business deal is made. For example, OOCL has sold her world class enterprise system to COSCO in early 2000, far before the COSCO merged with China Shipping. It may indicate a starting point for the public company of China, China COSCO Shipping to learn from the private or commercial company, OOCL via the system deployment, or a decision made even earlier as a good preparation of the future acquisition take place in terms of process, information and cash flows. This also allows the general public to forecast future acquisition in terms of system sharing. If Evergreen or Yang Ming or Wan Hai is arranged to use the master enterprise system developed by OOCL (and now owned by China COSCO Shipping), it might be a clear signal of acquisition in the foreseeable future.

Up to this moment, there is no news issued by all the mentioned shipping lines on system sharing or purchase, or resources sharing in terms of offices in regional and territorial level. The only relationship between China COSCO Shipping with one of these three Taiwan shipping lines is the alliance member or partner with Evergreen under the OCEAN alliance only. Therefore, it might not be likely for a prompt acquisition take place as preparation work is not observed so far. Political reason might be one of the key reasons, as Taiwan is being led by officials with strong competing intention with China in many aspects. However, this is not a permanent status and subject to change when change of leading officials take place. It is not impossible for new officials to offer full support for acquisition plan as a way to combine maritime strength and resources for a higher market share in resisting the domination shares from the West in the shipping market.

\section{New cooperation with quick response from headquarter equipment control team}

\subsection{Time for the next acquisition in the Greater China region}

While direct acquisition is not likely to take place in soon future, new cooperation dimension does exist but neglected so far. Most of the global shipping lines form global alliances for the purpose of offering regular weekly services in a large service scope covering all the developed and developing ports and regions. The key focus is used to be the handling of laden container export from those Asia countries to the West (Figure 5) according to the data obtained from the Hellenics shipping news report issued in 2017. The service loops are similar but not exactly the same among alliances. ECR could be considered as a new dimension for shipping lines from different alliances to cooperate with each other. For example, China COSCO Shipping could cooperate with Yang Ming from the The Alliance or the independent Wan Hai, other than Evergreen from the same alliance. Starting from the second quarter in 2017, the shipping market has indicated a stronger recovery that empty container become slack resources for many exporting regions in Asia. As the headquarters of these Chinese shipping lines share similar time zone in Asia, communication is fostered greatly without the need to wait for the next day reply for both intra- and inter-company communication in case of exceptional handling request raised by the regional office up to headquarter equipment control officers.
Equipment
planning
strategy for
liners

99 


\section{MABR}

3,1

\section{0}

\section{Figure 5.}

Estimated weekly capacity (TEU) for Asia-Europe and transpacific shipping service loops in June 2017 onwards

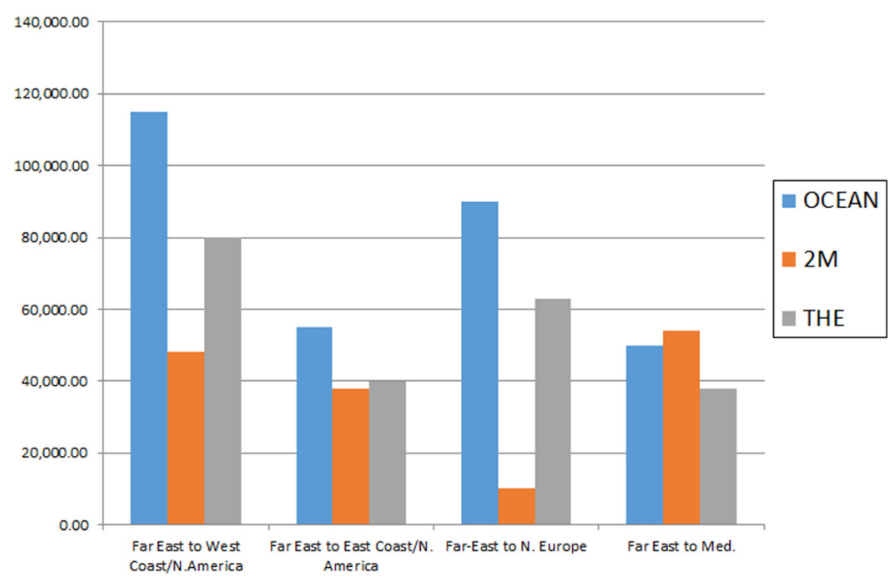

Source: Hellenics shipping news report 2017

\subsection{Synergy from empty container planning}

Before possible cooperation is elaborated in the next section, the empty container planning process is explained. Global shipping lines arrange ECR from the surplus regions to deficit regions by four-week rolling forecast. Regional office needs to submit empty container request to territorial (or headquarter) office for the upcoming four weeks. The request is supported by the local sales' communication with customers who might or might not have long-term service contract with the shipping line. The closer the week, the more accurate it is expected as empty container could not be added without vessel capacity planning in advance. On the other hand, officers from trade departments from territorial (or headquarter) tends to use most of the vessel capacity for laden containers that generate revenue. They expect the equipment (container) control or logistics department could solve the deficit problem by ad hoc short-term leasing arrangement. This shall add extra equipment cost that should be avoided unless it is absolutely needed as endorsed and supported by headquarter. Regional office could not arrange for leasing arrangement without approval from headquarter who oversee and manage the active container fleet and running cost. However, the forecast might not be accurate sometimes that additional amount of empty containers might be needed for the next week in a deficit region. The possibility to give up vessel capacity contributed to laden containers is often low that the central traffic control officer in headquarter level might persuade the regional officer to delay for the extra business that might be lost eventually. This gradually leads a high intention for local sales to stay with the proposed target sales volume as high volume might not be entertained at all.

On the contrary, ad hoc required additional containers for the extra business volume could be supported with a better ECR system or empty pool joined with multiple shipping lines. Local sales from each liner have much higher intention to push for a higher weekly target for a higher commission too. Especially when the vessel size is increased up to 20,000 TEU in 2017, short-term or segmented ride-thru empty boxes transported could be supported with the larger vessel capacity and power. At the same time, the demand at each region is smoothened, especially in the growing ports that ad hoc demand outbreak from time to time. The key problem is the empty pool system and repositioning logic setting as 
the liners are not under a common alliance now. The first possible step could be the setting up of the empty pool shall be constituted in terms of surplus port and region where service loops of liners passed through regularly. Under normal situation, the vessel-carrying capacity is applied for the profit-generating laden containers should be well-managed that certain amount of vessel capacities must be contributed or reserved for the ECR. For example, moving empty containers from the West (North American or European countries) back to the East (Table IV and Figure 6) according to the Hellenics shipping news report issued in 2017. When variance becomes big on ad hoc basis in either laden or empty container transport plan, the company might not be able to fulfill both laden and empty container with her existing capacity. With more liners join in the empty pool and repositioning system, liner could help to provide the needed ECR to ensure supply is close to target adequate level even the demand is increased suddenly. Laden container should not be

Size of container vessel ('000

TEU)

Before alliances' reform in April 2017

$18-21$

13.3-18

10-13.3

51

129

124

217

\section{3}

225

879

7.94

Total units (Vessel)

Total capacity ('000 TEU)

Source: Hellenics shipping news report 2017
Equipment planning strategy for liners

101
Table IV. Compare number of vessel and capacity

before and after alliances' reform in April 2017

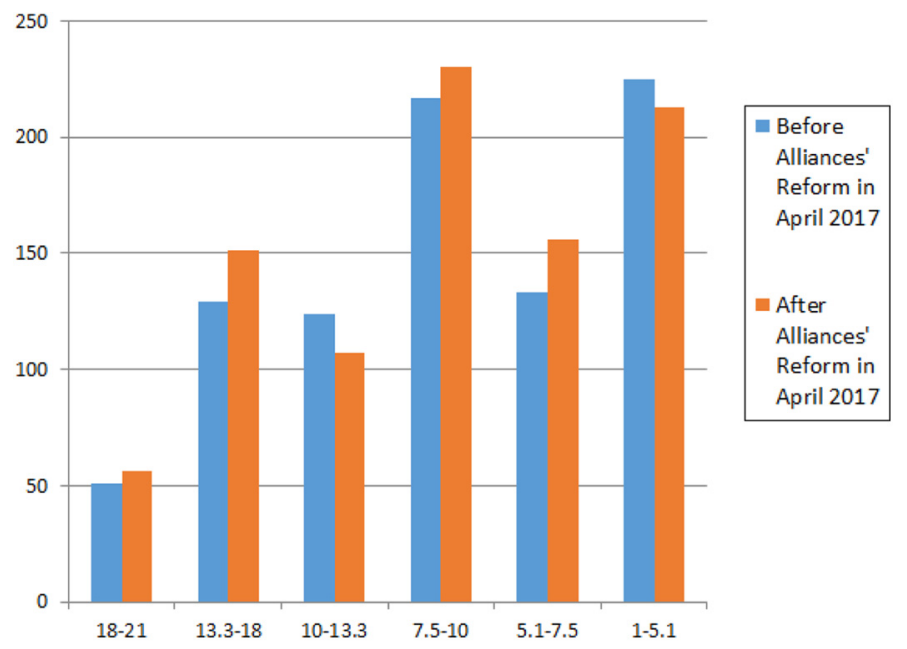

Source: Hellenics shipping news report 2017

Figure 6.

ECR by vessel with a wider size range 
MABR

3,1

102 arranged to other service route without the agreement of shipper, but empty container has much high flexibility. The empty pool repositioning system and pool details are explained in the following paragraphs.

\subsection{Possible cooperation on empty container}

3.3.1 Empty container repositioning by liners across alliances. Control officers from headquarter of cooperative liners is to communicate the remaining vessel capacity calling the concerned inbound port in the west certain hours or at the most one day before vessel departure. Cooperative liners could see the announcement and take the remaining capacity for ECR at an agreed unit cost agreed within the empty pool and system alliance. For simplicity, we name it empty container alliance that classified between the typical shipping alliance and the alliance focus on ECR system and pool only. Such short-term decisions must be made within the same or similar office hour between headquarters staff. They need to communicate with their corresponding territorial and regional offices by return for smooth execution without causing vessel delay or misunderstanding. For the three Taiwan Shipping lines, they share the same time zone with that of China COSCO Shipping. They are perfect candidates for forming this kind of empty container pool across alliances conceptually.

3.3.2 Improvement to free-use empty pool. Other than the ECR by the vessel about to depart from the West (European or North American ports), the empty container alliance liner members could leverage on the free-use container too. In the past, each liner member formulates free-use container arrangement with leasing company. The timeframe of these free-use containers is often short and usually up to three months. The liner must use these free-use containers for a well-matched cargo destination for efficient return of freeuse container to the next lessee, or else a high penalty cost shall be incurred. In the past, if the demand does not match with the previous foresee, large amount of free-use containers shall be accumulated in a region that finally incur additional cost instead of the planned cost saving. With the setting up of the empty container alliance, members could share any surplus free-use container and used by the other member. As long as proper agreement is passed with the leasing company, especially those sizable global leasing company who might also have free-use arrangement with all or some of the members, the demand is more stable. The chance of wasting free-use container will be much lower. The inventory cost of holding expired empty container will also be lowered too. Eventually, free-use arrangement might be signed in the proposed empty container alliance level instead of shipping line level that a larger volume shall be allowed that the empty container alliance member lines could bargain with the downstream service providers, namely, terminals, off-dock depots and trucking companies for better business deals, and result in lower unit cost eventually.

3.3.3 Pooling in empty container with deadlines before vessel departure time. Other than the free-use container, empty container alliance member lines could also pool out certain volume of empty containers for ad hoc support. The pool of container does not require a final balance in terms of number of containers, but balanced via a lump sum payment or a free ride-thru arrangement of an empty container for a certain port-pair or any other possible format of cooperation. This changed the historical concept totally that liners inter-change an empty container with a physical container only. With the empty container alliance membership, member lines could deal with members for the best way to return the value of the additional container obtained from the common empty pool. When the empty pool is not consumed by member line(s), it serves as a normal empty volume for each of the regional office to use for local export need. When there is a request to use the empty pool, the request 
needs to be voiced out at certain hours or a period before vessel departure at an interested port and region. Headquarter equipment control officer shall communicate with the corresponding territorial and regional office for the possibility to release the empty container (s) in the empty container alliance empty pool to member line. If there is no request voice out at a certain period before vessel departure, the empty container will be ceased and used by each owning line like normal. This added a new way to make sure empty containers, especially in the terminal with short storage time period, are retrieved and used for vessel loading. The classical way to avoid the storage cost is usually trailed to the off-dock deport, where the storage cost is lower. With the empty container alliance empty pool set up, each liner has more choices to ensure empty containers are active and moving without wastage. The next question is the amount of empty containers to be pooled in by each liner. As variance is different for each liner due to different customer base, the amount of empty containers vary on case by case basis.

3.3.4 Joint inspection and repair support. With the setting up of the empty container alliance, member lines could invest or hire container inspection and repair service jointly with lower unit cost. Customer require high quality container, especially for those ventilated container ( $\mathrm{RF}$ container), machinery must be checked before releasing to customer to store the temperature and/or humidity sensitive cargoes. The cost for inspection and repair is a significant part of the overall equipment variable cost in many shipping lines. The empty container alliance could also set up some kinds of service standards or certifications to the inspected and repaired containers, and release for customer who are willing to pay a higher premium for a set of containers with better quality. The main reason is the inspection and repair cost, in case of serious damage, is much lower in Asia countries when compare with that in the USA or Europe. Other than the extreme case of total loss, many minor to median damage containers are transported back to Asia that the empty container alliance could lower the repair cost via economies of scale, and set up a brand name and expertise in a long run to ensure steady supply of service with lower unit cost.

\section{Business implications}

ECR across alliances is a new concept for liners cooperate with higher flexibility in serving empty container demand. It offers high business opportunities for liners to be confident to conduct last minute business sales effort before the arrival of the concerned vessel for outbound cargoes. Even when the additional required empty container is not available from their own pick up locations in the region, the ECR alliance shall be a new source of empty containers. On the other hand, whenever liners that have demand less than the projected volume, they could have benefited with this efficient way to clear up any overdue empty container and avoid additional cost incurred due to detention charged by terminals or depots. The key business related questions are as follows:

- the design of the cooperative mechanism, including the estimation to the amount of containers pooled in by each liner in each port, as well as the choices of storage locations or common port(s) among all the possible and preferred locations of each liner; and

- the modeling of the relationship between the design and the demand change both locally and globally to achieve a robust design and effective application.

A good cost balancing and fairness evaluation is required to be available from the proposed alliance operating mechanism to ensure alliance functions properly and continuously that brings measurable benefits to involved liners.

\section{Equipment planning strategy for liners}

103 
MABR

3,1

104

\section{Conclusion}

To answer our first research question, acquisition among shipping lines in Asia and the Great China Region after China COSCO Shipping and OOCL acquisition case confirmed in July 2017 is expected to take place with a longer time line. Further acquisition is not likely to take place in 2018 or even 2019. This is based on the observed prolonged preparation time in terms of years, before the actual acquisition took place for the case of China COSCO Shipping and OOCL. It is also believed that a mega liner (with 20 per cent or above of the market share) may be formed further and led by China COSCO Shipping again only after successful re-organization between the two liners (China COSCO Shipping and OOCL) is completed. Nevertheless, during the re-structuring period in one or two years, setting up or joining empty container alliance is expected to speed up subsequent acquisition process. The intensive cooperation among potential liners who communicate simultaneously in daily operations is useful for liner's consideration, in terms of acquisition possibility. This kind of closer working relationship at all levels in each liner is useful in avoiding critical change in either side of the liners in terms of daily work flows when acquisition takes place. This gives an insightful answer to our second research question that empty container pool set up by liner members across alliances is considered as one of the effective solution to improve empty container shortage situations. Liner members within the same alliance share similar vessel schedules for the agreed service loops, and similar shortage situations may happen at the same time. It is suggested that liner should consider cooperating with liners from other alliances and take advantage to their different vessel arrival schedules, port rotations and vessel capacity arrangement for more effective shortage problem solving. In particular, shipping lines across alliances with headquarters in close proximity are potential candidates for such cooperation on empty container management. The new dimension enables equipment control and logistics officers in headquarter-level from liners across alliances who manage the equipment container pool communicate and cooperate closely. This enables more choices and solutions for all the involved liners. Alliance formation is not just limited to the classical vessel slot sharing purpose. With a new empty container pool among these Chinese shipping lines in PRC, Taiwan and Hong Kong SAR in particular, it is believed that a new communication platform could be created that shall foster the formation of mega shipping liner in Asia in the future. Mega shipping liners shall take a vital role along the roadmap laid down by the Government of China under the One-Belt-One-Road (OBOR) strategic plan and development in soon future. Further research opportunities on the detailed empty repositioning alliance formation considered and decided by prosperous liners to achieve sustainable business growth shall be a new and interesting area for further study in the future.

\section{Note}

1. This work is partially supported by the NSFC/RGC Joint Research Scheme (3-RAA7) and the PolyU LMS Departmental Learning and Teaching Enhancement Grant 1.44.xx.8AD1.

\section{References}

Agarwal, R. and Ergun, O. (2017), "Ship scheduling and network design for cargo routing in liner shipping", Transportation Science, Vol. 42 No. 2, pp. 175-196.

Alexandrou, G., Gouopulos, D. and Thomas, H.M. (2014), "Mergers and acquisitions in shipping", Transportation Research Part E, Vol. 61, pp. 212-234. 
Chao, S.L. and Lin, Y.L. (2017), "Gate automation system evaluation: a case of a container number recognition system in port terminals", Maritime Business Review, Vol. 2 No. 1, pp. 21-35.

Chen, J.H. and Yahalom, S. (2013), "Container slot co-allocation planning with joint fleet agreement in a round voyage for liner shipping", Journal of Navigation, Vol. 66 No. 4, pp. 589-603.

Equipment planning strategy for liners

Dong, J.X. (2013), "Assessment of empty container repositioning policies in Maritime transport", The International Journal of Logistics Management, Vol. 24 No. 1, pp. $49-72$.

Dong, J.X. and Song, D.P. (2009), "Container fleet sizing and empty container repositioning in liner shipping systems", Transportation Research Part E, Vol. 45 No. 6, pp. 860-877.

Epstein, R., Neely, A. and Weintraub, A. (2012), "A strategic empty container logistics optimization in a major shipping company”, Interfaces, Vol. 42 No. 1, pp. 5-16.

Lee, C.Y. and Song, D.P. (2017), "Ocean container transport in global supply chains: overview and research opportunities", Transportation Research Part B, Vol. 95, pp. 442-474.

Leng, P. (2003), "OOCL we take it personally”, Logistics Management, Vol. 42 No. 7, p. 98.

Li, Z.G., Yang, F.Y. and Zhang, D. (2016), “The virtual alliance knowledge sharing model and selection strategy", Computer Science, Vol. 91, pp. 276-283.

Lin, H.F. and Chang, K.L. (2016), "Key success factors of international market development: an empirical study of the Taiwan bulk shipping industry", Maritime Business Review, Vol. 2 No. 2 , pp. 79-98.

Lim, S.M. (1998), "Economies of scale in container shipping", Maritime Policy \& Management, Vol. 25 No. 4, pp. $361-373$.

Lu, H.A., Cheng, J. and Lee, T.S. (2006), “An evaluation of strategic alliances in liner shipping an empirical study of CKYH", Journal of Marine Science and Technology, Vol. 14 No. 4, pp. 202-212.

Moon, I.K., Do Ngoc, A.D. and Konings, R. (2013), "Foldable and standard containers in empty container repositioning", Transportation Research Part E, Vol. 49 No. 1, pp. 107-124.

Panayides, P.M. and Wiedmer, R. (2011), "Strategic alliances in container liner shipping", Research in Transportation Economics, Vol. 32 No. 1, pp. 25-38.

Song, D.P. and Carter, J. (2009), "Empty container repositioning in liner shipping", Maritime Policy \& Management, Vol. 36 No. 4, pp. 291-307.

Song, D.P. and Dong, J.X. (2011), "Effectiveness of an empty container repositioning policy with flexible destination ports", Transport Policy, Vol. 18 No. 1, pp. 92-101.

Sys, C. (2009), "Is the container liner shipping industry an oligopoly?", Transport Policy, Vol. 16 No. 5 , pp. 259-270.

Thai, V.V. (2008), "Service quality in Maritime transport: conceptual model and empirical evidence", Asia Pacific Journal of Marketing and Logistics, Vol. 20 No. 4, pp. 493-518.

Yang, C.S. (2016), "Evaluating the use of alternative Maritime power in Taiwan", Maritime Business Review, Vol. 1 No. 3, pp. 208-224.

Yip, T.L., Lun, Y.H. and Lau, Y.Y. (2012), "Scale diseconomies and efficiencies of liner shipping", Maritime Policy Management, Vol. 39 No. 7, pp. 673-683.

\section{Further reading}

Dessouky, M. and Carvajal, S. (2017), "Congestion reduction through efficient empty container movement", National Center for Sustainable Transportation, Research Report, August 2017.

Soppe, M., Parola, F. and Fremont, A. (2009), "Emerging inter-industry partnerships between shipping lines and stevedores: from rivalry to cooperationJournal of transport geography", Vol. 17 No. 1, pp. 10-20. 
MABR

3,1

106

Yang, D., Liu, M.J. and Shi, X.N. (2011), "Verifying liner shipping alliance's stability by applying core theory", Research in Transportation Economics, Vol. 32 No. 1, pp. 15-24.

Zhang, Y. and Facanha, C. (2013), "Strategic planning of empty container repositioning in the transpacific market: a case study", International Journal of Logistics, Vol. 17 No. 5, pp. 420-439.

Zheng, J.F., Gao, Z.Y., Yang, D. and Sun, Z. (2015), "Network design and capacity exchange for liner alliances with fixed and variable container demands", Transportation Science, Vol. 49 No. 4, pp. 886-899.

\section{Corresponding author}

Hang Fa Tong can be contacted at: hang-fa.tong@connect.polyu.hk

For instructions on how to order reprints of this article, please visit our website: www.emeraldgrouppublishing.com/licensing/reprints.htm

Or contact us for further details: permissions@emeraldinsight.com 